\title{
Cyclogenesis in the Mediterranean basin: a diagnosis using synoptic-dynamic anomalies
}

\author{
M. $\operatorname{Kaspar}^{1}$ and M. Müller ${ }^{1,2}$ \\ ${ }^{1}$ Institute of Atmospheric Physics AS CR, Prague, Czech Republic \\ ${ }^{2}$ Charles University, Faculty of Science, Prague, Czech Republic
}

Received: 26 March 2009 - Accepted: 18 June 2009 - Published: 25 June 2009

\begin{abstract}
This work deals with the hypothesis that synoptically-driven heavy rains in the Mediterranean region are connected with the occurrence of synoptic-dynamic anomalies. We investigate this hypothesis by conducting a diagnostic study of a cyclogenesis event from 18-21 July 2001. Cyclogenesis started over the western Mediterranean Sea and was triggered by the approach of a pre-existing upper trough over a lower frontal zone. The event was first accompanied by heavy convective rains in northern Italy and later by heavy, widespread and steady rains of non-convective character in Central Europe.

Using re-analyses from the database ERA-40, we evaluate the synoptic-dynamic anomalies by the cumulative distribution function relatively to July-August area-related climatology over the reference period from 1958 to 2002 . For the duration of cyclogenesis, we detect significant anomalies associated with the processes that support the completion of vertical coupling between the lower frontal zone and the upper vorticity maximum. The periods of heavy rains in both the Mediterranean region and Central Europe were characterised by the occurrence of anomalies that created synoptic-scale conditions favourable for triggering and sustaining heavy rains. Although these anomalies were somewhat weaker in the period of heavy rains in Central Europe than in the Mediterranean region, the analysis of their spatiotemporal correspondence over the reference rainfall events in the Czech Republic shows that they are typical of heavy rains there. Due to the relatively high variability of the causal synoptic-scale conditions, this study would benefit postprocessing procedures aimed at improving warning about
\end{abstract}

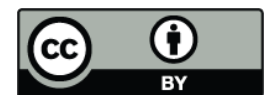

Correspondence to: M. Kaspar (kaspar@ufa.cas.cz) this hazardous weather phenomenon to further investigate which anomalies generally occur during synoptically-driven heavy rains in the Mediterranean region and the strengths of these anomalies.

\section{Introduction}

Most of the heaviest rains in the western Mediterranean region are attributed to mesoscale convective systems (Fernandez et al., 1995). Typically, such organised convection is dynamically driven by synoptic-scale processes, particularly in the eastward and poleward sectors of surface cyclones, where quasigeostrophic upward motions and sustained and intense low-level inflows of moist, potentially unstable air dominate (Martín et al., 2006; Jansá et al., 2001; Ramis et al., 1994). Considering this strong synoptic-scale forcing, an array of the conceptual models of causal synoptic-scale conditions was developed for use as a valuable complement to quantitative precipitation forecasting (Romero et al., 1999), for climatological studies of long-term rainfall variability (Campins et al., 2000), and for various sensitivity studies (Homar et al., 2007).

The cyclones that produce high impact weather in the Mediterranean region occasionally leave the Mediterranean basin and move to higher latitudes (Bocheva, 2007). They often reach Central Europe, where they belong to the most dangerous synoptic-scale circulation patterns in terms of precipitation totals (Kysely and Picek, 2007; Mudelsee, 2004). The cyclones are thermally asymmetric and contain extensive quasi-stationary rain bands in the cold rearward sector, where the heaviest rains of non-convective character occur (Ustrnul and Czekierda, 2001). Müller et al. (2009b) used

Published by Copernicus Publications on behalf of the European Geosciences Union. 
the close relationship between this synoptic-scale circulation pattern and heavy rainfall events in the Czech Republic (CR) to demonstrate that this pattern is regularly connected with the appearance of anomalous values of certain dynamic and thermodynamic variables in specific synoptic-scale areas. They referred to these areas as the synoptic-dynamic anomalies, and they showed that the combined strength of some of them is distinctly correlated with the intensity of heavy rains. The application of this finding is wide ranging. In particular, typical anomalies, which are characterised by high spatio-temporal correspondence during the events, can be used to analyse the synoptic-scale causes of heavy rains and as predictors in post-processing procedures aimed at improving the ability to warn against this hazardous weather phenomenon in the CR.

The results of the above-mentioned study and their possible applications motivated us to investigate the hypothesis that synoptic-dynamic anomalies also occur during heavy rainfall events in the Mediterranean region when strong synoptic-scale forcing is observed. We tested our hypothesis on a case of cyclogenesis over the western Mediterranean Sea that was accompanied by extraordinary convective activity between 18 and 21 July 2001 (Kurz and Fonatana, 2004). Since preliminary analyses supported the hypothesis, we decided to carry out a more comprehensive study; the most important results are presented in this work. We aimed at (i) describing the principles of the method used to detect and evaluate synoptic-dynamic anomalies, and (ii) discussing the most significant anomalies, which occurred immediately before and during heavy rains.

\section{Data and diagnostic methodology}

One approach used to detect and evaluate an anomaly in a meteorological variable is to express the anomalousness of the value of the variable relative to its distribution during a reference period. Since the climate generally varies by region, synoptic-dynamic anomalies should be considered separately in individual locations. A possible source of input data applicable to detecting and evaluating anomalies is the data from continuous re-analyses done over a sufficiently long time period.

\subsection{Detection of synoptic-dynamic anomalies}

We used re-analyses from the database ERA-40 (Uppala et al., 2005). The input dataset contains four re-analyses per day at 00:00, 06:00, 12:00, and 18:00 UTC in the 45-year period from 1 September 1957 to 31 August 2002. In the data processing, we focused on the domain covering a major part of Europe and the northern Atlantic $\left(30^{\circ} \mathrm{W}\right.$ to $40^{\circ} \mathrm{E}$ and $30^{\circ} \mathrm{N}$ to $70^{\circ} \mathrm{N}$ ) with a horizontal resolution of $2.5^{\circ}$. We defined the anomalousness of a value $x_{i}$ of a meteorological variable $X$ at a grid point of the domain by the point estima- tion of the cumulative distribution function $F_{X}\left(x_{i}\right)$, according to the formula (e.g., Kaspar et al., 2008b):

$F_{X}\left(x_{i}\right)=\frac{i}{N+1}$,

where $i$ is the number of values of $X$ less than or equal to $x_{i}$ and $N$ is the total number of values of $X$ at the grid point over a reference period. Considering that the right-hand side of Eq. (1) assesses the probability of not exceeding $x_{i}$, an $F_{X}\left(x_{i}\right)$ close to 0 corresponds to an extremely low $x_{i}$, while an $F_{X}\left(x_{i}\right)$ close to 1 corresponds to an extremely high $x_{i}$. The negative and positive anomalies in $X$ are then localised within limited, continuous areas containing grid points at which $F_{X}\left(x_{i}\right)$ approaches 0 and 1 , respectively. Taking into account the proximity of $F_{X}\left(x_{i}\right)$ to the endpoints of the interval $(0,1)$, it is practical to evaluate and compare the arearelated strengths of the anomalies. The quantitative aspect of this method for anomaly detection also enables the identification of the anomalies that regularly accompany heavy rainfall events using a method described in the following Sect. 2.2.

\subsection{Spatio-temporal correspondence of synoptic- dynamic anomalies}

In order to distinguish the synoptic-dynamic anomalies typical of heavy rainfall events, one must first quantify the similarity in the spatial distribution of the detected anomalies in specific phases of the events, for example, relative to the onset of precipitation. A method for evaluating such spatiotemporal correspondence of anomalies requires a set of reference heavy rainfall events as input information. These events should be selected using a unified methodology that enables their evaluation and comparison in terms of precipitation totals (Kaspar and Müller, 2008a; Müller et al., 2009a).

The presented method quantifies the spatio-temporal correspondence of the anomalous values of a variable $X$ in a specific phase of the events using the parameters $C_{X}^{(n)}$ for the negative anomalies and $C_{X}^{(p)}$ for the positive anomalies (Müller et al., 2009b), where:

$C_{X}^{(n)}=\sum_{i=1}^{k} v_{i} \sqrt{\prod_{i=1}^{k} F_{i}^{v_{i}}}$

and

$C_{X}^{(p)}=1-\sum_{i=1}^{k} v_{i} \sqrt{\prod_{i=1}^{k}\left(1-F_{i}\right)^{v_{i}}}$.

Equations (2) and (3) express the weighted geometrical mean of the point estimation of the cumulative distribution function $F$ defined in Eq. (1) over $k$ reference events, where $v_{i}$ denotes the properly assessed weights of the individual events. The typical negative and positive anomalies in $X$ are then localised within limited, continuous areas containing grid 

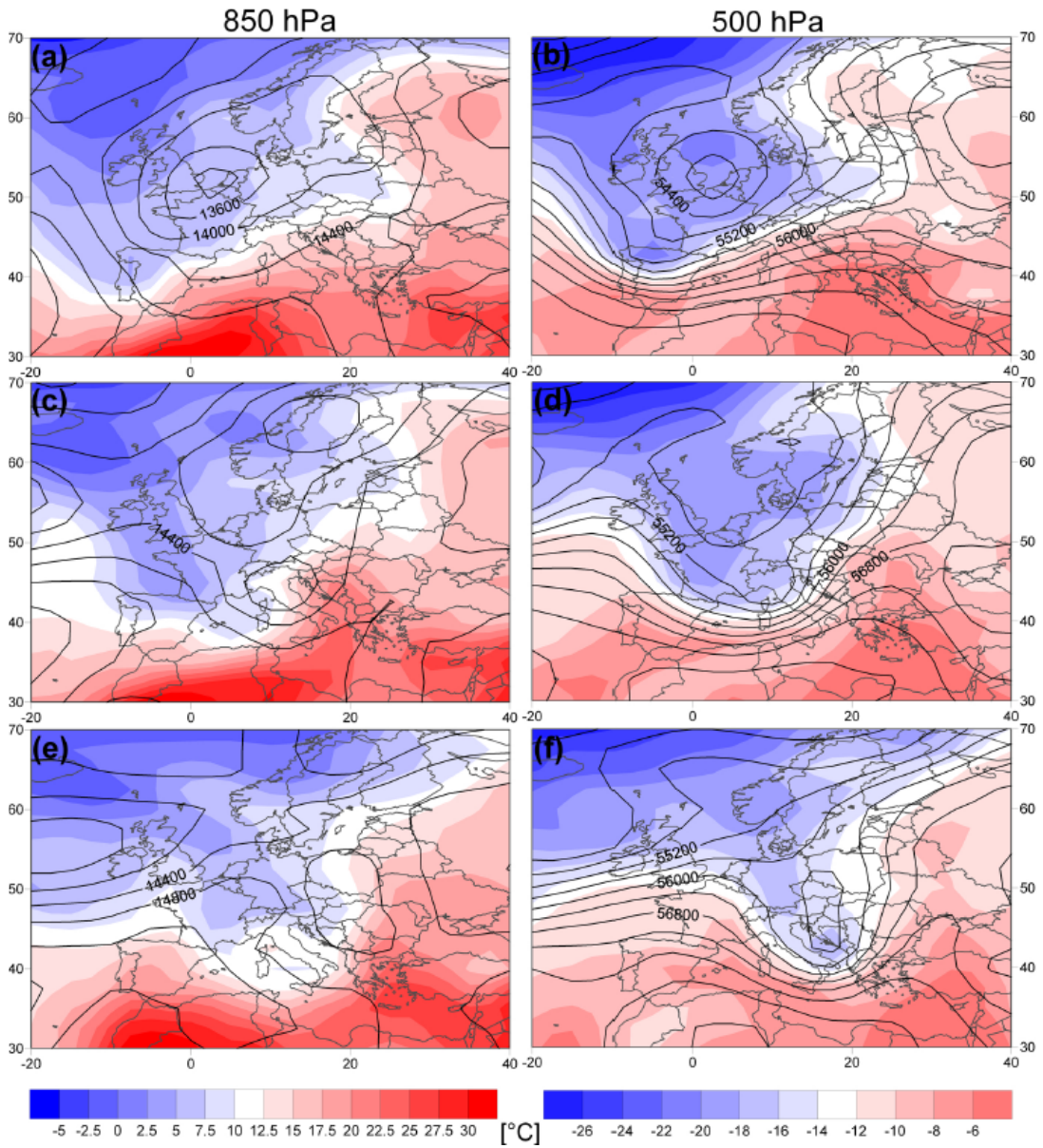

Fig. 1. ERA-40 re-analyses of temperature and geopotential fields (in units of gpdam) at 850 and $500 \mathrm{hPa}$ (from left to right) for the duration of the event: (a, b) 19 July 2001 at 00:00 UTC; (c, d) 20 July 2001 at 00:00 UTC; and (e, f) 21 July 2001 at 00:00 UTC.

points at which $C_{X}^{(n)}$ approaches 0 and $C_{X}^{(p)}$ approaches 1 , respectively.

Considering the natural variability in the synoptic-scale conditions of heavy rains, individual heavy rainfall events are caused by different variants of synoptic-scale circulation patterns; thus, the individual events are accompanied by different sets of anomalies. Nevertheless, most of the events have a degree of membership in more than one variant. Consequently, the events cannot be generally regarded as having equal weights $v_{i}$. In order to distinguish the typical anomalies for a particular variant, the weights should be proportional to the degree of membership of the individual events for this variant. In addition, if we want to use typical anomalies for a particular variant as potential predictors of heavy rains, then the weights should combine both the measure of the membership for this variant and the extremeness of the precipitation totals.

\section{Event 18-21 July 2001}

We examined the relationship between the occurrence of synoptic-dynamic anomalies and heavy rains in the Mediterranean region by conducting a diagnostic study of a cyclogenesis event from 18-21 July 2001 that arose over the western Mediterranean Sea. This event is appropriate for our purpose because it is characterised by strong synoptic-scale forcing and, at a later stage, relatively heavy rains, which, associated with the causal cyclone, also affected Central Europe.

\subsection{Event overview}

Synoptic-scale and mesoscale conditions, as well as the development and consequences of the event in the Mediterranean region, have already been analysed and demonstrated in detail by Kurz and Fotana (2004). Therefore, we summarise only the basic descriptive facts necessary for interpreting the results of the diagnosis presented in Sect. 3.2. We primarily follow the development of upper and lower thermo-baric fields for the duration of the event, as indicated in Fig. 1. 


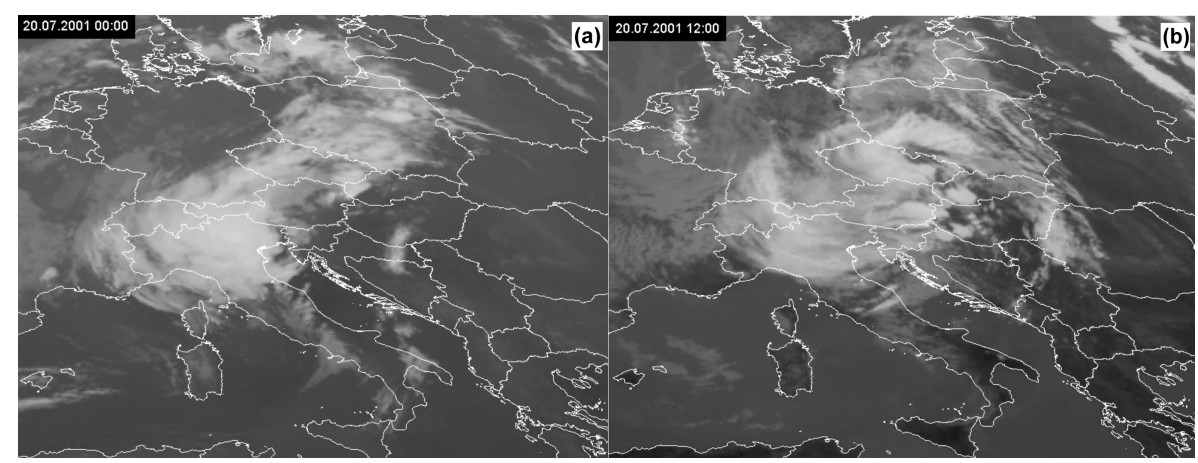

Fig. 2. METEOSAT infrared images: (a) 20 July 2001 at 00:00 UTC and (b) 20 July 2001 at 12:00 UTC (see also supplementary electronic material: http://www.nat-hazards-earth-syst-sci.net/9/957/2009/nhess-9-957-2009-supplement.zip).

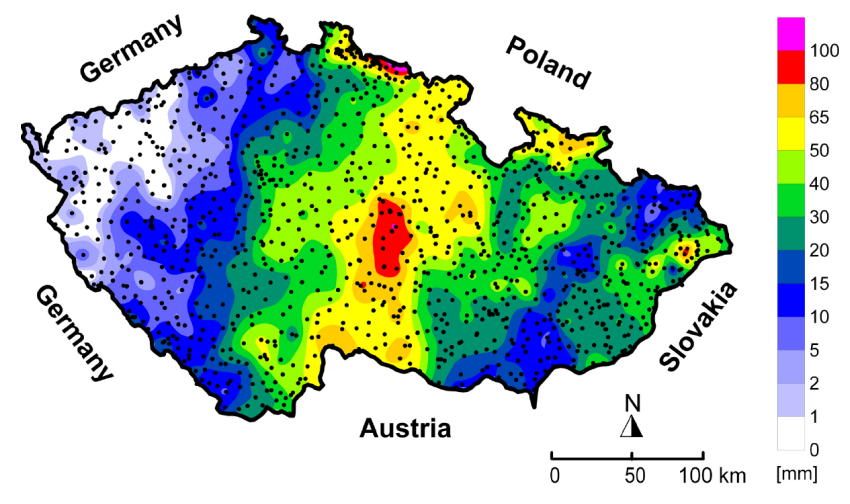

Fig. 3. Spatial distribution of 48 -h precipitation totals in the Czech Republic from 20 July 2001, 06:00 UTC to 22 July 2001, 06:00 UTC. The black dots indicate the positions of rain gauges.

The onset of the event was characterised by a verticallydeep cold air pool, an extensive surface and a collocated upper low over Western Europe (Fig. 1a, b). Cyclogenesis began near an initially quasi-stationary and lower frontal zone running from southern Spain to the Alps after 18 July, 12:00 UTC. Cyclogenesis took place according to the classic Petterssen scheme of a type B-development (Petterssen, 1971), where a pre-existing upper trough, connected to the upper low over Western Europe, spread over an area lacking cold thermal advection near the frontal zone. A closed surface cyclone with a central pressure below $1005 \mathrm{hPa}$ appeared east of the Balearics at about 12:00 UTC on 19 July.

The cyclone deepened and quickly moved to the north-east (Fig. 1c, d). During the evening and the night from 19 to 20 July, an organised convective system formed in the northeastern sector of the thermally asymmetrical cyclone. Extraordinary convective activity struck the plains of Veneto in northern Italy, bringing heavy rains, hail and stormy winds. The cloudiness associated with the convective system can be clearly identified in the infrared METEOSAT satellite picture in Fig. 2a. Besides strong synoptic-scale forcing, Kurz and Fontana (2004) stressed the important role of a pre- existing, significant vertical wind shear in the development of the storm. In addition, they showed the importance of potential instability at lower levels and the release of a large amount of latent heat at middle and upper levels in creating an environment conducive to severe convection, especially by increasing the convective available potential energy.

The convective system successively decayed on 20 July, while the weakening cyclone moved over eastern Central Europe (Fig. 1e, f). The cloud shield extended band-like in the north-easterly direction (Fig. 2b), and was connected with the development of extensive rain bands in the cold sector of the cyclone. These rain bands were accompanied by steady rains of generally non-convective character. In the CR, relatively high precipitation totals particularly affected the central parts of the territory, as shown in Fig. 3. On 21 July, the rains quickly ceased as the cyclone moved over the Balkans.

\subsection{Diagnosis using synoptic-dynamic anomalies}

In this section, we discuss the most significant anomalies in the dynamic and thermodynamic variables that occurred for the duration of cyclogenesis and during the periods of heavy rains in the Mediterranean region and Central Europe. We expressed the anomalousness of the values of the variables using $F$ defined in Eq. (1) relative to the July-August climatology (i.e., $N=11160$ ) to minimise the effect of the variability in the annual distribution. The variables considered are listed in Table 1.

\subsubsection{Mediterranean region}

Using Fig. 4, we first discuss the synoptic-dynamic anomalies that occurred immediately before the surface cyclone appeared. The approach of the pre-existing upper trough over the quasi-stationary lower frontal zone was connected to extremely intense cyclonic vorticity advection at upper levels (Fig. 4a). In accordance with quasigeostrophic theory, vertically-increasing vorticity advection ahead of the trough triggered synoptic-scale ascending motions, leading to the increase and extension of cyclonic vorticity downwards and 
Table 1. Description of the dynamic and thermodynamic variables used in the study.

\begin{tabular}{|c|c|c|c|}
\hline Variable & Abbreviation & Unit & Sign \\
\hline Advection of absolute vorticity & AAV & $\mathrm{s}^{-2}$ & $\begin{array}{r}\text { Cyclonal }(+) \\
\text { Anticyclonal }(-)\end{array}$ \\
\hline Moisture convergence & $\mathrm{CM}$ & $\mathrm{kg} \mathrm{m}^{-3} \mathrm{~s}^{-1}$ & $\begin{array}{r}\text { Convergence }(+) \\
\text { Divergence }(-)\end{array}$ \\
\hline Horizontal wind speed & HWS & $\mathrm{m} \mathrm{s}^{-1}$ & $(+)$ \\
\hline Meridional heat flux & MHF & $\mathrm{J} \mathrm{m}^{-2} \mathrm{~s}^{-1}$ & $\begin{array}{l}\text { Northerly (+) } \\
\text { Southerly (-) }\end{array}$ \\
\hline Meridional temperature gradient & MTG & $\mathrm{Km}^{-1}$ & $\begin{array}{l}\text { Northerly (+) } \\
\text { Southerly (-) }\end{array}$ \\
\hline Thermal advection & TA & $\mathrm{Ks}^{-1}$ & $\begin{array}{r}\text { Warm }(+) \\
\text { Cold }(-)\end{array}$ \\
\hline Vertical wind speed in p-system & VWS & $\mathrm{Pas}^{-1}$ & $\begin{array}{r}\text { Upward (-) } \\
\text { Downward (+) }\end{array}$ \\
\hline
\end{tabular}
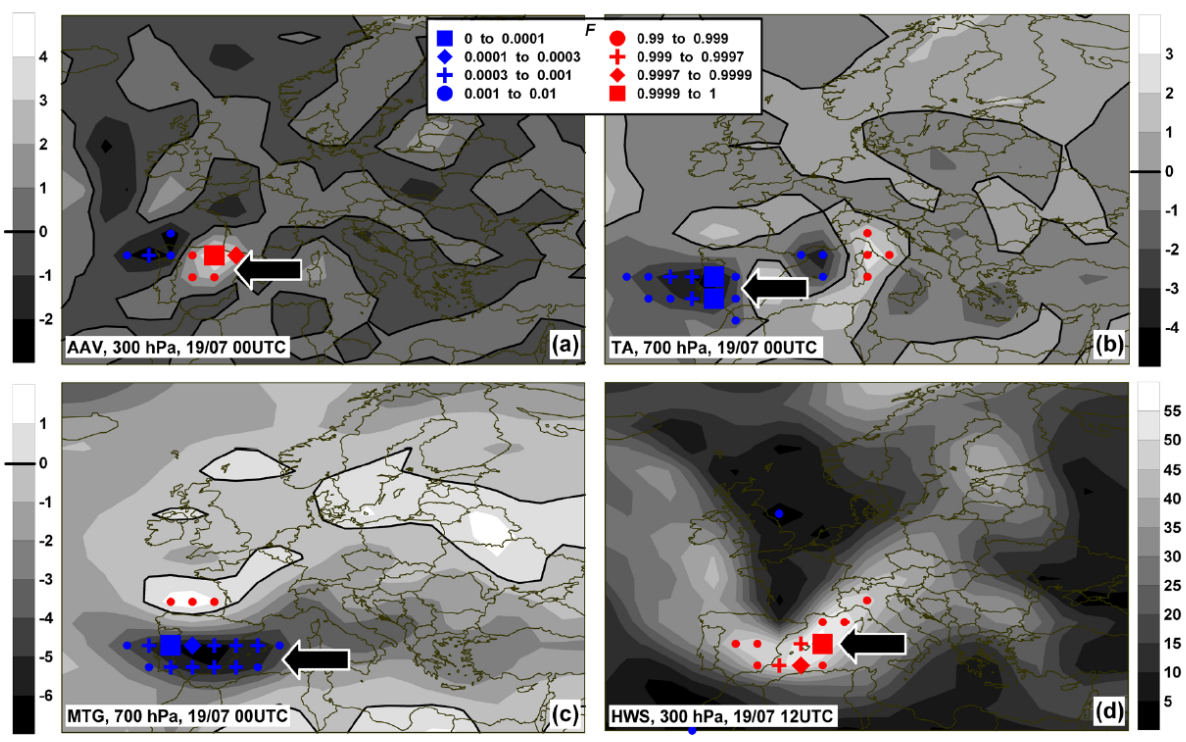

Fig. 4. Fields of selected variables and the anomalousness of their values expressed by $F$ immediately before the surface cyclone appeared: (a) advection of absolute vorticity at $300 \mathrm{hPa}$ (in units of $4 \times 10^{-9} \mathrm{~s}^{-2}$ ), (b) thermal advection at $700 \mathrm{hPa}$ (in units of $5 \times 10^{-5} \mathrm{~K} \mathrm{~s}{ }^{-1}$ ), (c) meridional temperature gradient at $700 \mathrm{hPa}$ (in units of $4 \times 10^{-6} \mathrm{~K} \mathrm{~m}^{-1}$ ), and (d) horizontal wind speed at $300 \mathrm{hPa}$ (in units of m s${ }^{-1}$ ).

downstream in a sloped zone. In addition, the approach of the trough was connected with extremely intense and verticallydeep cold thermal advection (Fig. 4b). Cold advection, which was apparently strengthened by ascending motions, caused a strong increase in baroclinity, especially at middle levels. Consequently, the frontal zone extended from lower levels upwards and sharpened, as can be demonstrated by an anomaly in the meridional temperature gradient at the middle levels (Fig. 4c). Finally, connected with this vertical extension, an upper jet streak abruptly intensified ahead of the trough (Fig. 4d). The above-mentioned processes contributed to the completion of vertical coupling between the frontal zone and the upper vorticity maximum, which resulted in the formation and further intensification of the causal cyclone (Kurz and Fontana, 2004).

Figure 5 shows the exceptionality of the synoptic-scale conditions when the organised convective system developed. While the initial surface cyclone deepened and moved quickly to northern Italy, an anomaly in the vertical wind speed arose throughout the troposphere in the north-eastern sector of the cyclone (Fig. 5a). The area of ascending motion was characterised by an extremely intense heat flux from the south (Fig. 5b), most likely due to the combined effect of the release of latent heat at the middle levels and lower warm thermal advection relative to the moving upper vorticity maximum. In addition, the area of ascending motions 


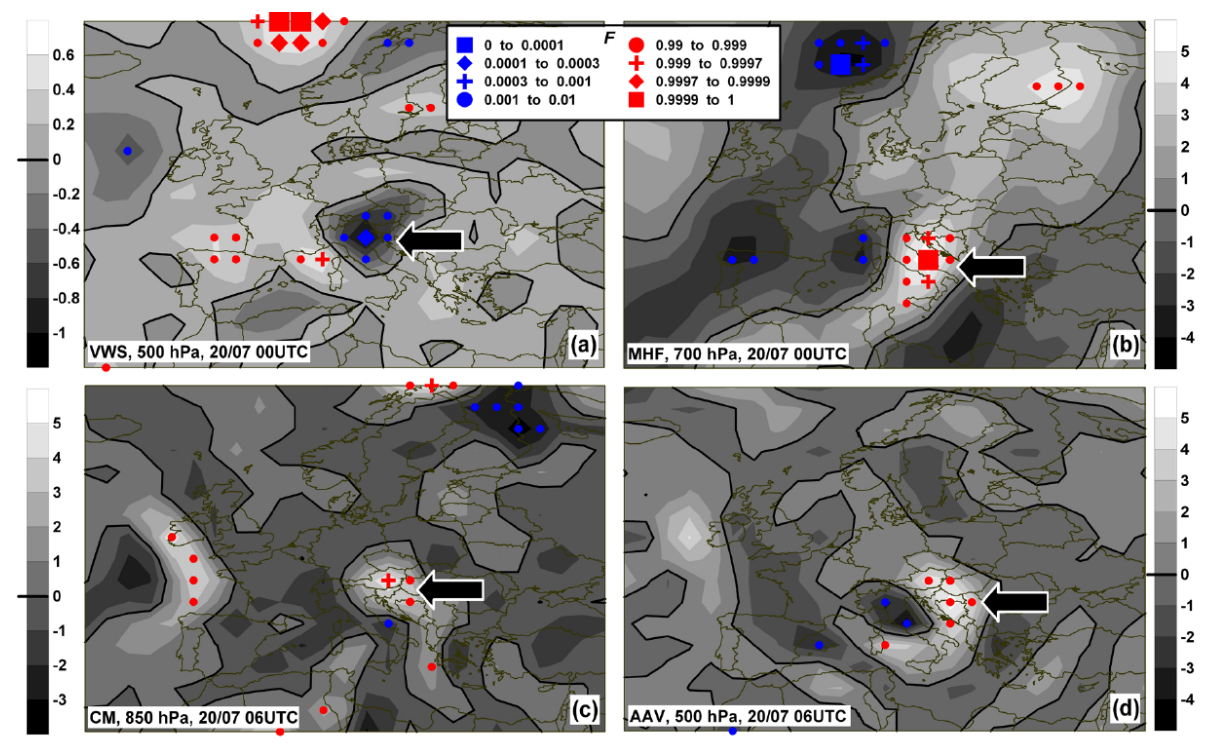

Fig. 5. Fields of selected variables and the anomalousness of their values expressed by $F$ when an organised convective system developed: (a) vertical wind speed at $500 \mathrm{hPa}$ (in units of $\mathrm{Pa} \mathrm{s}^{-1}$ ), (b) meridional heat flux at $700 \mathrm{hPa}$ (in units of $1 \times 10^{-6} \mathrm{~J} \mathrm{~m}^{-2} \mathrm{~s}^{-1}$ ), (c) convergence of moisture at $850 \mathrm{hPa}$ (in units of $5 \times 10^{-8} \mathrm{~kg} \mathrm{~m}^{-3} \mathrm{~s}^{-1}$ ), and (d) advection of absolute vorticity at $500 \mathrm{hPa}$ (in units of $8 \times 10^{-10} \mathrm{~s}^{-2}$ ).

was continuously supplied by the large amount of moisture at lower levels (Fig. 5c). Intense lower moisture convergence can explain, among other things, the development of potentially unstable lower layers that contributed to the increase of conditional instability when they were lifted to saturation by ascending motions. As a result, the main ingredients for deep, moist convection were provided (Doswell et al., 1998). Finally, when the cyclone was leaving the Mediterranean region, intense cyclonic vorticity advection occurred at upper levels to the north-east of the surface cyclone centre (Fig. 5d), which is in accordance with its movement over Eastern Central Europe.

\subsubsection{Central Europe}

The period of heavy rains in Central Europe was characterised by the occurrence of synoptic-dynamic anomalies localised particularly in the rainfall area, where they directly supported the increase in precipitation. Figures $6 \mathrm{a}$ and $\mathrm{b}$ show the two most significant anomalies detected, which were connected with vertically deep and relatively intense synoptic-scale ascending motions (Fig. 6a) and with intense lower moisture convergence (Fig. 6b). Unlike the Mediterranean region, where the same kinds of anomalies were detected (see Sect. 3.2.1), these anomalies, together with heavy rains, occurred in the cold part of the cyclone. Figure 7 compares the area-related strength of these anomalies between periods of heavy rains in the Mediterranean region and in Central Europe using the geometrical means of the grid point-related values of $F$ defined in Eq. (1). It is clear that both kinds of anomalies were somewhat weaker; furthermore, the anomaly in moisture convergence was substantially less extensive during the period of heavy rains in Central $\mathrm{Eu}-$ rope than in the Mediterranean region.

For completeness, we verified whether the abovediscussed anomalies are typical of heavy, widespread and steady rains in the CR. We evaluated the spatio-temporal correspondence of these anomalies using the set of the 38 heaviest July-August rainfall events compiled by Kaspar and Müller (2008a). For simplicity, we selected only the events that roughly corresponded to the same variant of causal synoptic-scale circulation patterns as the studied event. An objective criterion of the selection was the positioning of a local minimum in the $850 \mathrm{hPa}$ geopotential field at the grid point $\left[15^{\circ} \mathrm{E} ; 47.5^{\circ} \mathrm{N}\right]$ at the beginning of heavy rains. We obtained eight events in total, listed in Table 2. To a first approximation, the applied approach for selecting events enabled us to calculate the parameters $C_{X}^{(n)}$ and $C_{X}^{(p)}$ in Eqs. (2) and (3) using equal weights $v_{i}$. The resultant fields of $C_{\mathrm{VWS}}^{(n)}$ and $C_{C M}^{(p)}$ are depicted in Fig. $6 c$ and d, respectively. We conclude that the negative anomaly in the vertical wind speed (Fig. 6c) and the positive anomaly in the lower convergence of moisture (Fig. 6d) are typical of heavy rains in the CR.

\section{Conclusions}

Previous studies showed that synoptically-driven heavy rains in Central Europe were regularly connected with anomalous values of certain dynamic and thermodynamic variables in specific synoptic-scale areas. We used this finding to investigate whether the close relationship between synoptic-dynamic anomalies and heavy rains also exists in 

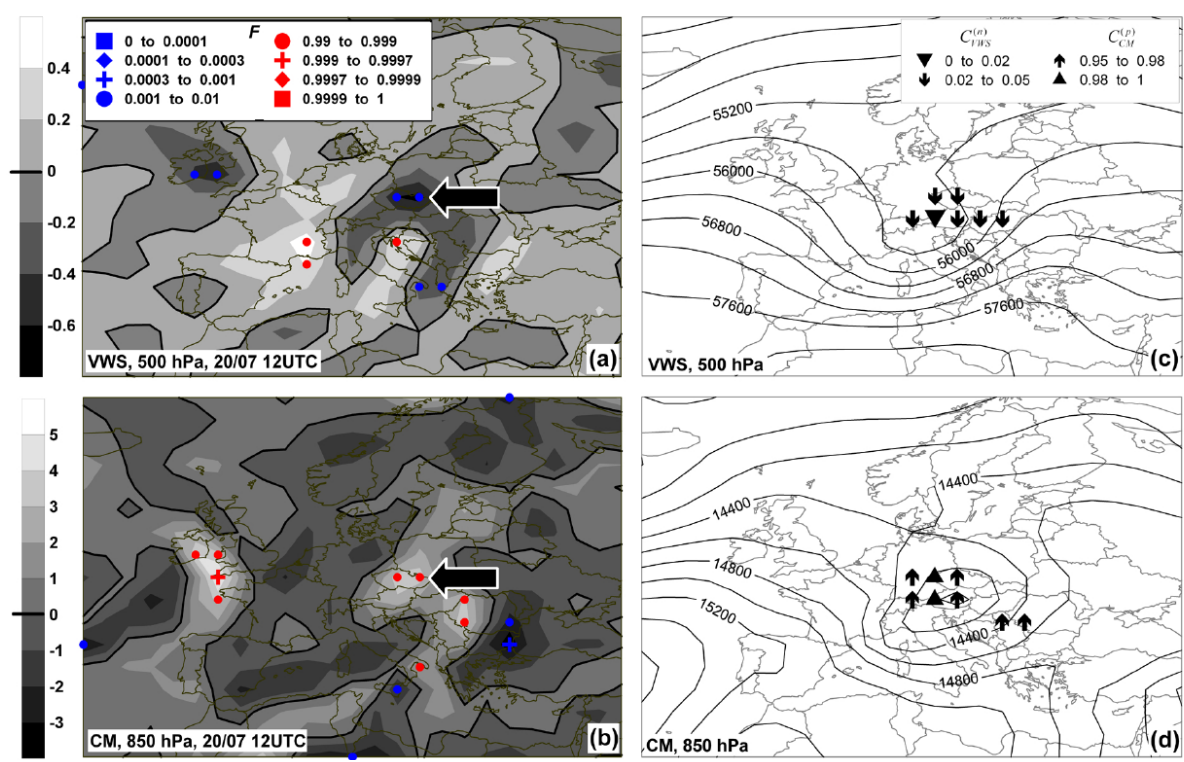

Fig. 6. Fields of selected variables combined with the anomalousness of their values expressed by $F$ when heavy, steady and widespread rains started to affect the Czech Republic (a, b), and the mean geopotential fields (in units of gpdam) combined with the spatio-temporal correspondence of the anomalies expressed by $C_{\mathrm{VWS}}^{(n)}$ and $C_{C M}^{(p)}$ at the approximate onset of the rainfall events stated in Table 2 (c, d): (a, b) the vertical wind speed at $500 \mathrm{hPa}$ (in units of $\mathrm{Pa} \mathrm{s}^{-1}$ ); and (c, d) convergence of moisture at $850 \mathrm{hPa}$ (in units of $5 \times 10^{-8} \mathrm{~kg} \mathrm{~m}^{-3} \mathrm{~s}^{-1}$ ).
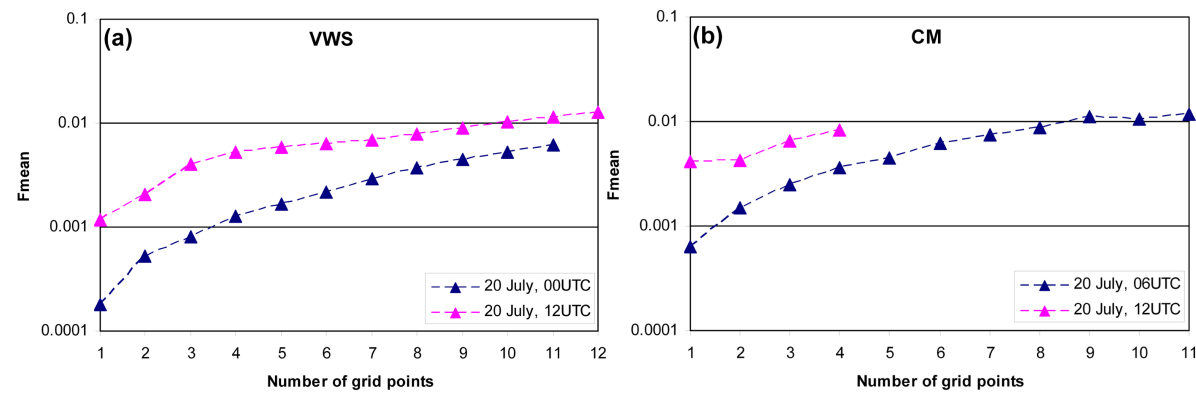

Fig. 7. Comparison of the area-related strength of the anomalies in the vertical wind speed (a) and the moisture convergence (b) during the periods of heavy rains in the Mediterranean region (dark blue marks) and the Czech Republic (pink marks). The area-related strength is evaluated by the minimum geometric mean of the grid point-related values of either $F<0.05$ (negative anomaly in the vertical wind speed) or $1-F<0.05$ (positive anomaly in the moisture convergence) within a continuous area containing a given number of grid points. The discussed anomalies are indicated by the arrows in Figs. 5a, c, 6a, and b.

the Mediterranean region when strong synoptic-scale forcing is observed. We investigated this hypothesis by conducting a diagnostic study of a cyclogenesis event that occurred from 18-21 July 2001. Cyclogenesis took place according to the classic Petterssen scheme of a type B-development over the western Mediterranean Sea, where a pre-existing upper trough approached over a lower frontal zone. The event was first accompanied by heavy convective rains in northern Italy and later by heavy, widespread and steady rains of nonconvective character in Central Europe.

Using re-analyses from the database ERA-40, we detected and evaluated synoptic-dynamic anomalies using the cumulative distribution function relative to July-August arearelated climatology over the reference period from 1958 to
2002. For the duration of cyclogenesis, we noted that the anomalies were associated with the processes supporting the completion of vertical coupling between the lower frontal zone and the upper vorticity maximum, namely: the upper anomaly in cyclonic vorticity advection over the frontal zone, the vertically-deep anomaly in cold thermal advection upstream of the frontal zone, the anomaly in the meridional temperature gradient near the frontal zone, and the upper anomaly in the horizontal wind speed ahead of the upper trough. The periods of heavy rains in both the Mediterranean region and Central Europe were characterised by the occurrence of anomalies that created synoptic-scale conditions favourable for triggering and sustaining heavy rains, in particular the occurrence of a vertically-deep anomaly in the 
Table 2. Reference rainfall events in the Czech Republic used to evaluate the spatio-temporal correspondence of the anomalies in Fig. 6.

\begin{tabular}{lrr}
\hline Event [yyyymmddhh] & $R x[\mathrm{~mm}]$ & Ranking of $R x$ \\
\hline 1959071518 & 19.6 & 32 \\
1977073112 & 36.4 & 9 \\
1977082200 & 20.8 & 29 \\
1991080100 & 24.2 & 25 \\
1997070512 & 75.0 & 1 \\
2000080612 & 18.1 & 34 \\
2001072012 & 30.4 & 14 \\
2002081118 & 47.1 & 2 \\
\hline
\end{tabular}

The first column contains the approximate onset of the event (in UTC) when a local minimum in the $850 \mathrm{hPa}$ geopotential field first occurred at the grid point $\left[15^{\circ} \mathrm{E} ; 47.5^{\circ} \mathrm{N}\right]$. The second column contains the highest value of a precipitation parameter $R x$ over specific sub-regions in the Czech Republic. The parameter is defined in Kaspar and Müller (2008a). It combines the mean daily areal precipitation amounts for the duration of heavy rains and a measure of the time concentration of precipitation. The third column contains the ranking of the $R x$ value in the period of high summer months (JA) from 1958 to 2002.

upward motion and a lower anomaly in moisture convergence near the rainfall area. Although these anomalies were somewhat weaker in the period of heavy rains in Central Europe than in the Mediterranean region, the analysis of the spatiotemporal correspondence over the reference rainfall events in the Czech Republic shows that the anomalies are typical of heavy rains there.

The presented diagnostic study demonstrates the similarity between the Mediterranean region and Central Europe from the perspective of synoptic-dynamic anomalies accompanying synoptically-driven heavy rains. Nevertheless, a systematic analysis of a set of reference rainfall events is needed to investigate which anomalies generally occur during synoptically-driven heavy rains in the Mediterranean region and the strength of these anomalies, in particular due to the relatively high variability of the causal synopticscale conditions. The acquired results would benefit postprocessing procedures aimed at improving warnings against this hazardous weather phenomenon.

Acknowledgements. This contribution was prepared with the support of the projects GAAVCR KJB300420701 and KJB300420802 and the research program MSM 0021620831. The ECMWF is acknowledged for the data from the database ERA-40. Precipitation data in the Czech territory and archive satellite images were kindly provided for research purposes by the Czech Hydrometeorological Institute.

Edited by: S. Michaelides

Reviewed by: two anonymous referees

\section{References}

Bocheva, L., Christo, G. G., and Simeonov, P.: A climatic study of severe storms over Bulgaria produced by Mediterranean cyclones in 1990-2001 period, Atmos. Res., 83, 284-293, 2007.

Campins, J., Genovesa, A., Jansa, A., Guijarro, J. A., and Ramis, C.: A catalogue and a classification of surface cyclones for the Western Mediterranean, Int. J. Climatol., 20, 969-984, 2000.

Doswell III, C. A., Ramis, C., Romero, R., and Alonso, S.: A diagnostic study of three heavy precipitation episodes in the Western Mediterranean region, Weather Forecast., 13, 102-124, 1998.

Fernandez, C., Gaertner, M. A., Gallardo, C., and Castro, M.: Simulation of a long-lived meso- bscale convective system over the Mediterranean coast of Spain. Part I: Numerical predictability, Meteorol. Atmos. Phys., 56, 157-179, 1995.

Homar, V., Jansá, A., Campins, J., Genovés, A., and Ramis, C.: Towards a systematic climatology of sensitivities of Mediterranean high impact weather: a contribution based on intense cyclones, Nat. Hazards Earth Syst. Sci., 7, 445-454, 2007, http://www.nat-hazards-earth-syst-sci.net/7/445/2007/.

Jansá, A., Genoves, A., Picornell, M. A., Campins, J., Riosalido, R., and Carretero, O.: Western Mediterranean cyclones and heavy rain.Part 2: Statistical approach, Meteorol. Appl., 8, 43-56, 2001.

Kaspar, M. and Müller, M.: Selection of historic heavy large-scale rainfall events in the Czech Republic, Nat. Hazards Earth Syst. Sci., 8, 1359-1367, 2008a, http://www.nat-hazards-earth-syst-sci.net/8/1359/2008/.

Kaspar, M., Müller, M., Kakos, V., Rezacova, D, and Sokol, Z.: Severe Storm in Bavaria, the Czech Republic and Poland on 1213 July 1984: a statistic- and model-based analysis, Atmos. Res., 93, 99-110, 2009.

Kurz, M. and Fontana, A. D.: A case of cyclogenesis over the western Mediterranean Sea with extraordinary convective activity, Meteorol. Appl., 11, 97-113, 2004.

Kysely, J. and Picek, J.: Probability estimates of heavy precipitation events in a flood-prone central-European region with enhanced influence of Mediterranean cyclones, Adv. Geosci., 12, 43-50, 2007 , http://www.adv-geosci.net/12/43/2007/.

Martín, M. L., Santos-Munoz, D., Morata, A., Luna, M. Y., and Valero, F.: An objectively selected case study of a heavy rain event in the Mediterranean Basin: A diagnosis using numerical simulation, Atmos. Res., 81, 187-205, 2006.

Mudelsee, M., Börngen, M., Tetzlaff G., and Grünewald, U.: Extreme floods in central Europe over the past 500 years: Role of cyclone pathway "Zugstrasse Vb", J. Geophys. Res., 109, D23101, doi:10.1029/2004JD005034, 2004.

Müller, M., Kaspar, M., and Matschullat, J.: Heavy rains and extreme rainfall-runoff events in Central Europe from 1951 to 2002, Nat. Hazards Earth Syst. Sci., 9, 441-450, 2009a, http://www.nat-hazards-earth-syst-sci.net/9/441/2009/.

Müller, M., Kaspar, M., Rezacova, D., and Sokol, Z.: Extremeness of meteorological variables as an indicator of extreme precipitation events, Atmos. Res., 92, 308-317, 2009b.

Petterssen, S. and Smebye, S. J.: On the development of extratropical cyclones, Q. J. Roy. Meteorol. Soc., 97, 457-482, 1971.

Ramis, C., Llasat, M. C., Genovrs, A., and Janszi, A.: The October1987 floods in Catalonia: Synoptic and Mesoscale Mechanisms, Meteorol. Appl., 1, 337-350, 1994. 
Romero, R., Sumner, G., Ramis, C., and Genovés, A.: A classification of the atmospheric circulation patterns producing significant daily rainfall in the Spanish Mediterranean area, Int. J. Climatol., 19, 765-785, 1999.

Uppala, S. M., Kållberg, P. W., Simmons, A. J., Andrae, U., Da Costa Bechtold, V., Fiorino, M., Gibson, J. K., Haseler, J., Hernandez, A., Kelly, G. A., Li, X., Onogi, K., Saarinen, S., Sokka, N., Allan, R. P., Andersson, E., Arpe, K., Balmaseda, M. A., Beljaars, A. C. M., Van De Berg, L., Bidlot, J., Bormann, N., Caires, S., Chevallier, F., Dethof, A., Dragosavac, M., Fisher, M.,
Fuentes, M., Hagemann, S., Hólm, E, Hoskins, B. J., Isaksen, L., Janssen, P. A. E. M., Jenne, R., McNally, A. P., Mahfouf, J. F., Morcrette, J. J., Rayner, N. A., Saunders, R. W., Simon, P., Sterl, A., Trenberth, K. E., Untch, A., Vasiljevic, D., Viterbo, P., and Woollen, J.: The ERA-40 re-analysis, Q. J. Roy. Meteorol. Soc., 131, 2961-3012, 2005.

Ustrnul, Z. and Czekierda, D.: Circulation background of the atmospheric precipitation in Central Europe (based on the Polish example), Meteorol. Z., 10, 103-111, 2001. 